\title{
The Inaugural Issue of The Hip \& Knee Journal
}

\author{
Nicolaas C. Budhiparama1,2,3,4, Sholahuddin Rhatomy ${ }^{5}$, Asep Santoso ${ }^{6}$ \\ ${ }^{1}$ Nicolaas Institute of Constructive Orthopaedic Research \& Education Foundation, Medistra Hospital, Jakarta, Indonesia \\ ${ }^{2}$ Department of Orthopaedic \& Traumatology, Faculty of Medicine, Public Health \& Nursing, Universitas Gadjah Mada, Yogyakarta, \\ Indonesia \\ ${ }^{3}$ Faculty of Vocational Studies, Universitas Airlangga, Surabaya, Indonesia \\ ${ }^{4}$ Department of Orthopaedic and Traumatology, Leiden University Medical Center, Leiden, The Netherlands \\ ${ }^{5}$ Department of Orthopaedic \& Traumatology, Dr. Soeradji Tirtonegoro General Hospital Klaten, Universitas Gadjah Mada, Indonesia \\ ${ }^{6}$ Department of Orthopaedic \& Traumatology, Prof. Dr. R. Soeharso Orthopaedic Hospital, Universitas Sebelas Maret, Surakarta, \\ Indonesia
}

The Indonesian Hip \& Knee Society (IHKS) was formed in 2007 and has a long tradition of having remarkable scientific programs during its biennial scientific meetings due to the participation of world renowned speakers from all over the world. One of IHKS goals is to have its own scientific journal in order to accommodate knowledge sharing among orthopaedic surgeons specializing in hip and knee problems.

Welcome to the inaugural issue of The Hip \& Knee Journal, the official journal for Indonesian Hip and Knee Society. We aim to publish peer-reviewed papers on the topic of adult reconstruction, sports medicine, trauma and general biology surrounding the hip and knee, from basic to advanced. We accept manuscripts on original research, systematic review, meta-analysis, current concept review and case studies on rare, unique and thought-provoking cases that will invoke further discussions or change the practice of medicine.

Hip \& Knee Journal aims to encourage orthopaedic surgeons to publish their works and share their experiences in order to improve patient care. Hip \& Knee Journal will be your partner to publish your researches or reviews and grow together.

\section{The Silver Lining of COVID-19 Pandemic}

The Coronavirus Disease 2019 (Covid-19) Pandemic has impacted orthopaedic surgery globally [1]. It is also true for orthopaedic practice in Indonesia. Since the first confirmed Covid-19 case had been reported in Indonesia in early March 2020, all aspects of medical practice in Indonesia have been disrupted. The Indonesian Orthopaedic Association (IOA) had also released its official recommendation to postpone all elective orthopaedic surgical services including Arthroplasty and Arthroscopy.
The same impact has also been reported among hip and knee surgeons worldwide [2,3]. The volume in hip and knee elective surgeries have been significantly reduced.

One of the possible positive impacts of this situation is that most surgeons now have more time for their scientific research work. The orthopaedic publications have been significantly increased during this pandemic period. To accommodate social distancing, surgeons get many more opportunities to sit down and evaluate all the patients' data they have collected over the years and write up their findings. As part of this journal's contribution to the difficult situation of Covid-19 pandemic, we may also accept a paper which presents issues related to Covid-19 to help the spread of the critical information among the readers. We hope that you would submit your results so we can share it with other surgeons for further analysis and comparison with their own findings. This will open the window of opportunities for surgeons from different areas to collaborate on multi center studies

\section{The Lost Art of Research}

The advancement of orthopaedic science depends on the education of young surgeons, either through their research efforts, their residency training until their clinical practices. Residency training often focus on clinical rather than research competence [4]. Once they graduate, they dive right into the healthcare system to gain their clinical experience. Unfortunately, the economic pressure of National healthcare system and shortage of surgeons in the suburban areas are turning surgeons into technicians who need to operate to ensure a healthy margin for their hospitals [5]. 
This leaves surgeons with no time or energy to dedicate for research. Research competence is actually not gained during medical studies but can be categorized into the ability to synthesize and draw conclusion from findings; the ability to do literature search and appraise the research findings critically; and lastly, the ability to form research question as a hypothesis and analyse data [4].

Orthopaedic surgeons need to keep up with the latest updates on results of surgical techniques and technologies so they can differentiate and judge for themselves which works and which does not. Surgeons should be able to use other's research result and conduct their own. Let us use this opportunity to resurrect the art of research amongst us.

\section{Abstracting / Indexing}

We will continue to work hard to establish the Journal as one of the most professional and authoritative academic publications in the hip and knee field. The Hip \& Knee Journal is prepared to be included in the reputed journal indexing, such as SINTA, Scopus, and PubMed. As a new journal, we realize the journey will not be easy. However, we believe with high commitment and support, our target can be achieved in the future.

\section{References:}

1. Wong JSH, Cheung KMC. Impact of COVID-19 on Orthopaedic and Trauma Service: An Epidemiological Study. J Bone Joint Surg Am. 2020;102(14):e80. doi:10.2106/JBJS.20.00775

2. Bedard NA, Elkins JM, Brown TS. Effect of COVID-19 on Hip and Knee Arthroplasty Surgical Volume in the United States. J Arthroplasty. 2020;35(7S):S45-S48. doi:10.1016/j.arth.2020.04.060

3. D'Apolito R, Faraldi M, Ottaiano I, Zagra L. Disruption of Arthroplasty Practice in an Orthopedic Center in Northern Italy During the Coronavirus Disease 2019 Pandemic. J Arthroplasty. 2020;35(7S):S6-S9. doi:10.1016/j.arth.2020.04.057

4. Marz R, Dekker FW, Van Schravendijk C, O’Flynn S, Ross MT. Tuning Research
Competences for Bologna 3 cycles in Medicine: Report of a MEDLINE European Consensus Survey. Perspect Med Educ. 2013;2:181-195

5. Evers BM. The Evolving Role of Surgeon Scientist. J Am Coll Surg. 2015;220:387395 